\title{
Makine Öğrenme Yöntemleri ile Semen Kalitesi Tahmini
}

\author{
Kerim Karadağ ${ }^{1 *}$ \\ ${ }^{1}$ Harran Üniversitesi, Mühendislik Fakültesi, Elektrik-Elektronik Mühendisliği, Şanlıurfa, Türkiye (ORCID: 0000-0001-5167-4054)
}

(İlk Geliş Tarihi 31 Aralık 2019 ve Kabul Tarihi 29 Şubat 2020)

(DOI: 10.31590/ejosat.668500)

ATIF/REFERENCE: Karadağ, K. (2020). Makine Öğrenme Yöntemleri ile Semen Kalitesi Tahmini. Avrupa Bilim ve Teknoloji Dergisi, (18), 306-311.

Öz

Doğurganlık oranları son yıllarda önemli ölçüde azalmıştır. Bu durum özellikle erkeklerde daha fazla görülmeye başlanmış ve kısırlık olarak ifade edilmiştir. Kısırlık, Dünya Sağlık Örgütüne göre seksüel olarak aktif bir çiftin herhangi bir önlem alınmadan bir yıl süreyle düzenli cinsel ilişlkide bulunmasına rağmen gebeliğin oluşmamasıdır. Kısırlık, sebebi ne olursa olsun üreme sağlığı sorunudur. Sperm fonksiyonunun bozulması, erkek kısırlığının en önemli nedenlerinden biridir. Kısırlığın bir diğer etmeni de semen kalitesi ve sperm hareketsizliğidir. Yaşam alışkanlıkları ve çevresel faktörler insanlarda semen kalitesini etkileyip doğurganlık oranını azaltmaktadır. Semen analizi erkek doğurganlık potansiyelinin iyi bir göstergesidir. Bu yüzden spermin hareketliliği, yoğunluğu ve morfolojisi semen analizinde incelenmektedir. Bu analizler uzmanlarca laboratuvar ortamında yapılmaktadır. Laboratuvarda analizler, gözleme dayalı hataya açık ve subjektif olabilmektedir. Bu tür hataları minimize edebilmek için Bilgisayar destekli çalışmalar kullanılmaktadır. Bu çalışmada 100 denekten alınmış semen örnekleri ve yapılan anket sonuçlarına göre oluşturulan veri seti makine öğrenme algoritmaları kullanılarak normal ve değiştirilmiş semen tahmini yapılmıştır. Tahmin modellerinde, Destek Vektör Makineleri, K En Yakın Komşuluk, Doğrusal Ayırt Edici ve Lojistik Regresyon yöntemleri kullanılmıştır. Çalışmada elde edilen performans değerleri, literatürdeki benzer çalışmalarla kıyaslanarak problemin çözümüne ilişkin en uygun tahmin algoritmaları tespit edilmiştir. Bozulmuş ve normal semen örnekleri tahmin yapma işlemi makine öğrenme yöntemleri kullanılarak yapılmış ve iki aşamada değerlendirilmiştir. İlk olarak tüm veri seti kullanılmış ve daha sonra veri seti sayısı eşit alınarak başarı oranları karşılaştırılmıştır. Eğitim ve test işlemi için kullanılan veri seti ilk olarak çapraz doğrulama yapıllarak değerlendirilmiş ve daha sonra veri setinin eğitim ve test değerleri $\% 50 \% 50$ alınarak işleme alınmıştır. Sınıflandırma sonuçlarında performans ölçütü olarak, doğru tahmin edilen örneklerin tüm örneklere oranı kullanılmıştır. Tüm veri seti kullanılarak elde edilen başarı sonuçları, Destek Vektör Makineleri ve K En Yakın Komşuluk yöntemleri ile \%90 olmuştur. Verisetinde normal ve bozulmuş semen örnekleri eşit olmadığı için sayıca az olan bozulmuş semen örnekleri kadar normal semen örnekleri kullanılmış ve bu şekilde 7 değerlendirme durumu sağlanmıştır. Bu şekilde elde edilen en yüksek başarı oranı 4. değerlendirme durumu için Destek Vektör Makineleri kullanılarak \% 91.7 olmuş ve 7 değerlendirme durumu ortalaması için ise en yüksek başarı durumu K En Yakın Komşuluk yöntemi kullanılarak $\% 73,8$ olmuştur.

Anahtar Kelimeler: Semen Kalitesi, Makine Öğrenme Algoritmaları, Tahmin, Sınıflandırma.

\section{Semen Quality Estimation by Machine Learning Methods}

\begin{abstract}
Fertility rates have decreased significantly in recent years. This situation has started to be seen especially in men and it has been expressed as infertility. According to the World Health Organization, infertility is the absence of pregnancy even though a sexually active couple has regular sexual intercourse for one year without taking any precautions. Infertility is a reproductive health problem
\end{abstract}

\footnotetext{
* Sorumlu Yazar: Harran Üniversitesi, Mühendislik Fakültesi, Elektrik-Elektronik Mühendisliği, Şanlıurfa, Türkiye, ORCiD: 00000001-5167-4054, k.karadag@harran.edu.tr
} 
for whatever reason the cause. Impairment of sperm function is one of the most important causes of male infertility. Another factor of infertility is semen quality and sperm immobility. Life habits and environmental factors affect the quality of semen in humans and reduce fertility. Semen analysis is a good indicator of male fertility potential. Therefore, motility, density and morphology of sperm are examined in semen analysis. These analyzes are performed in the laboratory by experts. Laboratory analyzes can be observational, error-prone, and subjective. Computer-aided studies are used to minimize such errors. In this study, normal and altered semen estimation was performed by using machine learning algorithms, which were formed according to the results of the questionnaires and semen samples taken from 100 subjects. In estimation models, Support Vector Machines, K Nearest Neighborhood, Linear Discriminant and Logistic Regression methods were used. The most suitable estimation algorithms for the solution of the problem were determined by comparing the performance values obtained in the study with similar studies in the literature. Deteriorated and normal semen samples were estimated using machine learning methods and evaluated in two stages. First, the entire data set was used, and then the success rates were compared by taking the number of data sets equally. The data set used for the training and testing process was first evaluated by cross-validation and then the training and test values of the data set were $50 \%-50 \%$ processed. In the classification results, the ratio of correctly predicted samples to all samples was used as performance criteria. The success results obtained using the whole data set were $90 \%$ with the Support Vector Machines and the K Nearest Neighborhood methods. Since normal and impaired semen samples are not equal in the dataset, normal semen samples are used as much as the impaired semen samples, which are few in number, and thus provided 7 evaluation cases. The highest success rate achieved in this way was $91.7 \%$ using Support Vector Machines for the 4th evaluation case, and for the average of 7 evaluation status, the highest success was $73.8 \%$ using the K Nearest Neighborhood method.

Keywords: Semen Quality, Machine Learning Algorithms, Estimation, Classification.

\section{Giriş}

Üreme, canlıların soylarının devamı için kendilerine benzer bireyler oluşturmaları olarak tanımlanır. Üreme sorunlarından biri olan kısırlık ise her ne sebeple olursa olsun, sperm fonksiyonunun bozulmasıdır. Bu durum erkek üremesini olumsuz yönde etkileyen nedenlerdendir (Shiva ve ark., 2011). Kısırlığı etkileyen faktörlerin başında semen kalitesi gelir. Semen analizi erkeğin üreme kapasitesini öngörebilmek amacıyla ejakülatın makroskobik ve mikroskobik özelliklerinin değerlendirilmesidir (Gökçe ve ark., 2018). Yaklaşık son çeyrekte yapılan çalışmalardan görüldüğü üzere semen parametrelerinde azalmaların olduğu görülmektedir. Bu azalmaları etkileyen faktörler arasında erkek üreme hastalıklarının artışı yer almaktadır. Ayrıca çevresel veya mesleki faktörlerin etkisi de görülmüştür. Bu durum erkek doğurganlık potansiyelini etkilemektedir. Semen analizi erkek doğurganlık potansiyelinin iyi bir göstergesidir (Gil ve ark., 2012). İyonik ortamın sperm fonksiyonu üzerinde yüksek etkisinin olduğu bilinir (Hamameh ve Gatti, 1998). Semen parametrelerinin zaman içinde çok ciddi değişiklikler gösterebileceği örneğin fertil erkeklerde dahi zamansal ve mevsimsel farklılıklar oluşturabileceği bilinmelidir. Bundan dolayı semen analizi değerlendirmesinde birden çok incelemenin yapılması doğruluk derecesinin artması açısından önem arz etmektedir (Tapısız ve ark., 2012). Bu konu ile ilgili yapılan çalışmalar incelendiğinde; Pesch ve ark. bazı enzimlerin ve makro ve mikro elementlerin ve semen kalitesi ile korelasyonunun belirlenmesini incelemişler (Pesch ve ark., 2006). Pesini ve ark. yaptıkları çalışmalarında, spektrofotometrik olarak ölçülen mitokondriyal enzim aktiviteleri ve seminogram parametreleri arasında doğrudan bir ilişki olduğunu göstermişler (Ruiz-Pesini ve ark., 2000). Shiva ve ark. yaptıkları çalışmalarında oksidatif stres ve seminal antioksidan aktivitenin sperm kalitesi üzerine etkisini incelemişler (Shiva, M., Gautam ve ark., 2011). Genital sistem enfeksiyonu, sadece sperm hücre fonksiyonunu değil, tüm spermatogenezi etkileyen, erkek kısırlığının en önemli nedenidir. Maciejewska ve ark. bu enfeksiyon ve semen kalitesi arasındaki ilişki ile ilgili olarak bir çalışma yapmışlar (Sanocka-Maciejewska ve ark., 2005). Xu ve ark. çalışmalarında semen kalitesi, insan spermatozoasında oksidatif DNA hasarı ve seminal plazmada kadmiyum, kurşun ve selenyum konsantrasyonları arasındaki ilişkiyi incelemişler (Xu ve ark., 2003). Chı ve ark yaptıkları çalışmalarında infertil ve fertil erkeklerde kandaki çinko konsantrasyonları ile seminal plazma ve sperm kalitesi arasındaki ilişkileri incelemişler (Chıa ve ark. 2000). Ramlau-Hansen ve ark. çalışmalarında, çok sayıda sağlıklı erkekte mevcut sigara içmeyle semen özelliklerinin hormonal düzeyleri arasındaki ilişkiyi araştırmışlar (Ramlau-Hansen ve ark., 2006). Irgens ve ark. infertil çiftlerde sperm kalitesinin düşmesinin doğurganlık için tehlikeli olduğu bilinen mesleki risklerle ilişkili olup olmadığını gösteren bir çalışma yapmışlar (Irgens ve ark., 1999). Yapılan bir başka çalışmada gürbüz ve ark., infertilite ve semen kalitesi ile insan seminal plazmasındaki total karnitin konsantrasyonları arasındaki korelasyonu belirlemeye çalışmışlar (gürbüz ve ark., 2003). Stutz ve ark., çalışmalarında sağlıklı genç erkeklerde alkol, tütün ve aspirin tüketiminin seminal kalite üzerine etkisini incelemişler (Stutz ve ark. 2004). Demirci yaptığı çalışmada erkek fertilitesinde riskli olabilecek yaşam biçimi davranışları ve bu konuda yapılmış çalışmaları gözden geçirmiş (Demirci, 2014). Hamlacı ve ark., iş hayatının erkek üreme sağlığına etkisini incelemişler (Hamlacı ve ark., 2017). Latif ve ark. yaptıkları çalışmalarında, 1977-2010 yılları arasında Danimarka'nın Frederiksberg Hastanesinde kısırlık için görülen 5.370 hastayı gözlemleyerek semen kalitesinin genel sağlığın güçlü bir biyobelirteç olduğu önerisini desteklemişlerdir (Latif ve ark., 2017). Makine öğrenme yöntemleri kullanılarak yapılmış semen ile ilgili çalışmalara örnekler verilecek olunursa, Amann ve waberski bilgisayar destekli sperm analizi çalışması yapmışlar (Amann ve Waberski, 2014). Helwan ve ark yaptıkları çalışmalarında, hastalarla ilgili bazı özellikleri kullanarak semen kalitesinin değerlendirilmesine radyal temelli sinir ağını uygulamışlardır (Helwan ve ark., 2016). Simfukwe ve ark. semen kalitesi tahmini ile ilgili yaptıkları çalışmalarında Yapay sinir ağları ve Naive bayes yöntemlerini kullanmışlardır (Simfukwe ve ark., 2015). Candemir yaptığı çalışmada, Radyal temel fonksiyon sinir ağlarını kullanarak semen kalitesini yaşam tarzı, çevresel faktörler ve günlük alışkanlıklardan tahmin etmek için kullanmıştır (Candemir, 2018). Bidgoli ve ark. yaptıkları çalışmada semen örneklerini sınıflandırmak üzere yapay sinir ağının yapısını optimize etmek için genetik bir algoritma kullanmışlardır (Bidgoli ve ark.,2015). Uyar ve ark. yaptıkları çalışmalarında tüp bebek tedavisi başarı iyileştirmesinde makine öğrenimine dayalı karar destek sisteminin yararlı olacağını göstermişler (Uyar ve ark., 2015). Wang ve ark. yaptıkları çalışmalarında, seminal kalite tahmininde dengesiz sınıf öğrenme problemiyle başa çıkmak için yeni bir denetimli topluluk öğrenme yaklaşımı, yani 
Kümelenme Tabanlı Karar Ormanları önermişler (Wang ve ark. 2014). Hicks ve ark. yaptıkları çalışmalarında, insan sperm örneklerinin 85 videosundan ve ilgili katılımcı verilerinden oluşan bir veri kümesiyle birlikte sperm motilitesini otomatik olarak tahmin etmek için modern ve klasik makine öğrenme tekniklerini kullanmışlardır (Hicks ve ark., 2019).

Çalışmamızda kullanılan veriseti (Gil ve ark., 2012), Alicante Üniversitesi öğrencileri arasında genç sağlıklı gönüllü 18-36 yaş arası 100 katılımcının semen örnekleri ve anket sorularına verdiği cevaplardan oluşmuştur. Makine öğrenme algoritmaları kullanılarak sınıflandırma işlemi yapılmış ve en yüksek skorların elde edildiği, benzer çalışmalarda da kullanılan dört sınıflandırılma yöntemi kayda alınmıştır.

\section{Materyal ve Metot}

\section{1. Çalış̧mada Kullanılan Veri Seti}

Çalışma Alicante Üniversitesi öğrencileri arasında genç, sağlıklı (varikosel rahatsızlı̆̆ı olmayan) gönüllülerle yapıldı. Katılımcılar 18-36 yaş aralığında 100 gönüllüden oluşturuldu ve gönüllüler bilgilendirildikten sonra 3 ila 6 günlük cinsel yoksunluktan sonra semen örnekleri vermeleri istendi. Semen parametrelerini etkileyen çeşitli faktörlerden biri olan cinsel perhiz süresi, Dünya Sağlık Örgütü tarafından önerilen semen değerlendirme kılavuzlarında yer alan bir kriterdir (WHO, 2010). Semen örneklerinin yanı sıra gönüllülerden yaşam alışkanlıkları ve sağlık durumu hakkında bir anket doldurmaları istendi. Ankette semen kalitesine doğrudan veya dolaylı etkisi olabilecek sorular eklenerek bireylerin cevapları doğrultusunda bir değerlendirilme yapıldı. Tablo 1, çalışmada kullanılan değişkenlerin adı, değer aralığını ve normalize edilmiş değerler gösterilmektedir. Çalışmada Uci Fertility Data Set kullanılmıştır (Gil ve ark., 2012).

Tablo 1. Çalı̧̧mada Kullanılan Veri Seti Özellikleri

\begin{tabular}{|c|c|c|}
\hline Değişkenler & Gerçek Değgerler & Normalize Edilmiş Değerler \\
\hline Mevsim & Klş; İlkbahar; Yaz ve Sonbahar & $(-1 ;-0,33 ; 0,33$ ve 1$)$ \\
\hline Yaş & $18 \sim 36$ & $(0 ; 1)$ \\
\hline Çocukluk Hastalıklart & Evet; Hayır & $(0 ; 1)$ \\
\hline Kaza ve Tramvalar & Evet; Hayır & $(0 ; 1)$ \\
\hline Cerrahi Müdaheleler & Evet - Hayır & $(0 ; 1)$ \\
\hline Son Bir Yllda Geçirdiği Yüksek Ateş & $\begin{array}{c}3 \text { aydan daha az; } 3 \text { aydan daha } \\
\text { fazla ve Haylr }\end{array}$ & $(-1 ; 0 ; 1)$ \\
\hline Alkol Tüketim Slklığl & Günlük; Haftalık ve Hayır & $(0 ; 1)$ \\
\hline Sigara İçme Allşkanlı̆̆ & Hayır; Ara sıra; Her gün & $(-1 ; 0 ; 1)$ \\
\hline Günlük Oturma Süresi & $1 \sim 16$ & $(0 ; 1)$ \\
\hline Sопис̧ & Normal; Değiştirilmiş & $(0 ; 1)$ \\
\hline
\end{tabular}

Girdilerin değerlendirilmesi aşağıdaki kurallara göre normalizasyon işlemine alınmıştır; Yaş, Günlük ortalama sigara sayısı gibi sayısal değişkenler $(-1 ; 1)$ ile normalleştirilmiş. Sadece iki bağımsız niteliğe sahip değişkenler, ikili değerlerle $(0 ; 1)$, üç bağımsız niteliğe sahip olan değişkenler, üçlü değerler kullanılarak $(-1 ; 0 ; 1)$ ve dört bağımsız niteliğe sahip değişkenler ise dört farklı ve eşit mesafe değeri kullanılarak $(-1 ;-0.33 ; 0.33,1)$ normalize edilmiştir. Toplam 9 değişken, 100 örnekten oluşan verisetinin 12 tanesi normal ve 88 tanesi değiştirilmiş semen örneğinden oluşmuştur.

\section{2. Çalışmada Önerilen Sistem}

Bu çalışma kapsamında önerilen semen kalitesi tahmin akış şeması Şekil 1'de verilmiştir. Bu çalışmada UCI "Fertility Data Set" verileri kullanılmıştır. Veriseti düzenleme ve özellik seçme önişlemlerinden sonra Matlab R2018a kullanılarak makine öğrenme algoritmaları uygulanmıştır. Makine öğrenme algoritmaları olarak; Destek Vektör Makineleri (DVM), K En Yakın Komşuluk (KNN), Lojistik Regresyon (LR) ve Doğrusal Ayırt Edici (DAE) kullanılmıştır. Sonuçta sağlıklı ve değiştirilmiş semen kalite tahmini yapılmıştır.
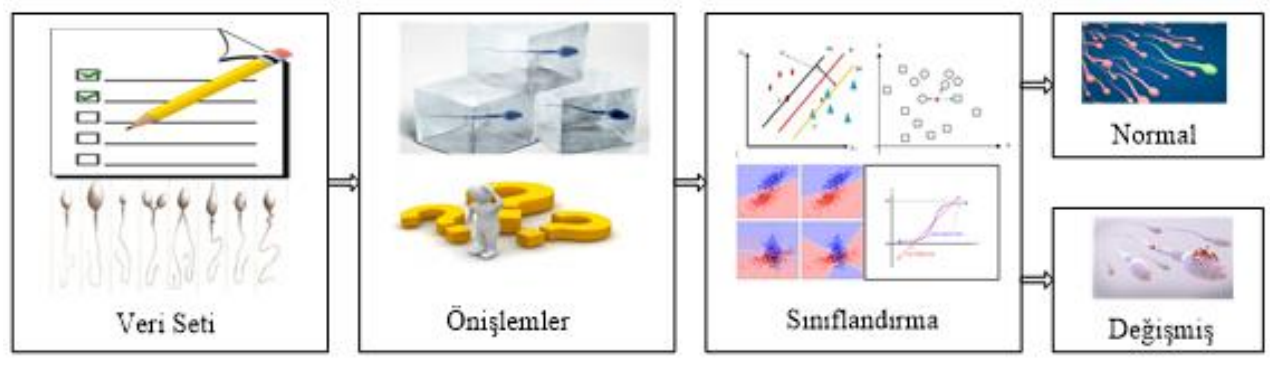

Şekil 1. Semen kalitesi tahmininde izlenen işlem akışı 


\section{3. Çalışmada Kullanılan Yöntemler}

Semen durum tahmini için makine öğrenme algoritmaları kullanılmıştır. Bu algoritmaların temel amacı hesaplama yöntemlerini kullanarak veriden bilgi elde etmeyi sağlamaktır. Kullanılan birçok farklı yöntem vardır, fakat doğru algoritmaların seçimi önemlidir. Bu çalışmada; DVM, KNN, LR ve DAE yöntemleri kullanılmıştır. DVM yöntemi, farklı sınıflara ait veri setini birbirinden en uzak olacak şekilde, aynı sınıfa ait veri kümelerini ise en yakın olacak şekilde ayırmaya çalışan bir yöntemdir (Gümüşçü ve ark., 2018). KNN yöntemi, sınıflandırma işlemi için en yakın komşu sayısı k’yı seçer ve k'nın grup üyeliğine göre verileri sınıflandırır. LR yöntemi, bağımlı değişken ile bağımsız değişkenler arasındaki ilişkiyi, temel lojistik fonksiyonunu kullanarak olasılıkları tahmin ederek ölçer (Gültepe, 2019). DAE yöntemi ise, önceden bilinen özellikleri, gerçek sınıflarına en doğru şekilde atamayı amaçlayan çok değişkenli istatistiksel bir yöntemdir (Alkan ve ark., 2018).

\section{Araştırma Sonuçları ve Tartışma}

Çalışmada kullanılan veriseti, deneklerin anketlere vermiş oldukları cevaplar ve alınan semen örnekleri ile oluşturulmuştur. Elde edilen 100 örnekten, 12'si normal ve 88'i bozulmuş semen örneklerinden oluşmuştur. Örnek dağılımı eşit olmamasına rağmen yapılan ilk uygulamada tüm veriseti, normalizasyon işlemine tabi tutulmuş ve makine öğrenme yöntemleri kullanılarak sınıflandırma işlemine alınmıştır. En yüksek sonuçların elde edildiği yöntemler; DVM, KNN, LR ve DAE olmuştur. Veri seti ilk başta 5 Çapraz Doğrulama (ÇD) ile ayrılıp sınıflandırma işlemine konulmuş daha sonra \% 50 si eğitim, \% 50 si test olacak şekilde işleme alınmıştır. Elde edilen başarı oranları $10 \mathrm{kez}$ tekrar edilip DVM, KNN, LR ve DAE yöntemleri kullanılarak başarı oranları en düşük \%82 ve en yüksek \%94 olarak kayda alınmıştır. Tablo 2'de, 10 tekrarın başarı ortalamaları ve saniye olarak süreleri verilmiştir. Başarı oran yüzdelikleri, tahmin edilen doğru sayısının tüm veri setine bölünerek hesaplanması ile elde edilmiştir.

\section{Tablo 2. Tüm Veriseti Kullanılarak Elde Edilen Ortalama Başarı Oranları}

\begin{tabular}{|c|c|c|c|c|}
\hline \multirow[t]{2}{*}{ Kullanılan Yöntemler } & \multicolumn{2}{|c|}{$C ̧ D$} & \multicolumn{2}{|c|}{ Ĕgitim \%50 - Test \%50 } \\
\hline & $\begin{array}{c}\text { Başarı Oranı } \\
(\%)\end{array}$ & $\begin{array}{l}\text { Süre } \\
\text { (San) }\end{array}$ & $\begin{array}{c}\text { Başarı Oranı } \\
(\%)\end{array}$ & $\begin{array}{l}\text { Süre } \\
\text { (San) }\end{array}$ \\
\hline$D V M$ & 90 & 0.124 & 90 & 0.0583 \\
\hline$K N N$ & 90 & 0.119 & 90 & 0.0573 \\
\hline$D A E$ & 84 & 0.141 & 82 & 0.0586 \\
\hline$L R$ & 84 & 0.307 & 80 & 0.1240 \\
\hline
\end{tabular}

Sınıflandırma işleminde kullanılan en yüksek ortalama başarı oranı her iki durum için \%90 olarak elde edilmiştir. Gil ve ark. aynı veri setini kullanarak Karar Ağaçları, Çok Katmanlı Algılayıcı ve Destek Vektör Makineleri yöntemleri kullanarak en yüksek başarı oranını \% 86 olarak bulmuşlar (Gil ve ark., 2012). Veri setinin orantısız dağılımından dolayı (88 normal, 12 değiştirilmiş) elde edilen performansların aldatıcı olacağı düşünülerek normal ve değiştirilmiş sonuçlar harmanlanarak eşit sayıda kullanılıp tekrar sınıflandırma işlemine alınmıştır. Fakat yinede tüm örneklerin değerlenirmeye tabi tutulamayacağı göz önüne alınarak normal olan 12 semen örneği ve diğer değiştirilmiş semen örneklerinden 12 tanesi alınarak 7 değerlendirme durumu oluşturulmuştur. (Herbir durum için 12 normal ve 12 değiştirilmiş semen örneği yeralmıştır.) Sonuçlar tüm verisetinin kullanıldığı gibi ilk başta 5 çapraz doğrulama ile ayrılıp sınıflandırma işlemine konulmuş daha sonra \% 50 si \% 50 si test olacak şekilde işleme alınmış ve elde edilen ortalama değerler tablo 3 te verilmiştir.

Tablo 3. Normal ve Değişmiş Semen Özellikleri Eşit Sayıda Kullanılarak ÇD ve \%50 Ĕ̌itim - \%50 Test ile Elde Edilen Başarı Oranlarl

\begin{tabular}{|c|c|c|c|c|c|c|c|c|c|c|c|c|c|c|c|c|}
\hline & \multicolumn{2}{|c|}{ l Dĕ̆.Dur. } & \multicolumn{2}{|c|}{2 Değ.Dur } & \multicolumn{2}{|c|}{3 Değ.Dur } & \multicolumn{2}{|c|}{4 Dĕ̆.Dur } & \multicolumn{2}{|c|}{5 Değ.Dur } & \multicolumn{2}{|c|}{6 De ̆.Dur } & \multicolumn{2}{|c|}{7 Değ.Dur } & \multicolumn{2}{|c|}{ Ortalama } \\
\hline$K N N$ & 58.3 & 75 & 70.8 & 50 & 70.8 & 83.3 & 87.5 & 83.3 & 70.8 & 66.7 & 79.2 & 83.3 & 70.8 & 75 & 72.6 & 73.8 \\
\hline$D A E$ & - & - & 54.2 & 50 & 66.7 & - & 70.8 & 66.7 & 79.2 & 66.7 & 79.2 & 66.7 & 54.2 & 50 & 67.38 & 60 \\
\hline
\end{tabular}

Bu çalışmada, 100 gönüllü 18 - 36 yaş aralığında genç deneklerden alınan semen örneklerden normal ve değiştirilmiş semen kalitesinin tahmini yapılmaya çalışılmıştır. Tüm veri seti kullanıldığında en yüksek başarı oranı DVM ve KNN yöntemleri kullanılarak ortalama \% 90, veriseti normal ve değiştirilmiş semen örneklerinden eşit alındığında ise en yüksek başarı oranı DVM yöntemi kullanılarak 4. değerlendirme durumunda \%91.7 olmuştur. Aynı veriseti kullanılarak yapılmış çalışmalar incelendiğinde genelde tüm verisetinin kullanıldığı görülmüştür. Fakat normal ve değişmiş semen örneklerinin dengesiz dağılımından dolayı elde edilen sonuçların aldatıcı olacağı düşünülmüş ve çalışmalara ilave olarak normal ve değişmiş semen örneklerinin eşit alındığı 7 değerlendirme durumu oluşturulmuştur. 


\section{Sonuç}

Sperm analizi erkek kısırlığında ilk ve temel test olarak kullanılmaktadır. Kişinin kısırlığı hakkında fikir verebilmesi için sperm analizinin toplanması ve analizi standart bir uygulama ile yapılmalıdır. Bu uygulamalara katkı sunacak şekilde kullanılan bilgisayar destekli çözümler faydalı olacaktır. Sonuç olarak, makine öğrenme yöntemlerinden DVM, KNN, LR ve DAE kullanılarak12'si normal 88'i değiştirilmiş 100 genç denekten alınan semen örnekleri ve anketlere verilen cevaplardan oluşan veri setinden semen kalite tahmini yapılmıştır. Kullanılan sınıflandırma yöntemleri ile elde edilen sonuçların yüksek olması, seçilen öznitelik parametrelerinin doğru parametreler olduğunu ve hekimlere teşhis koymada fikir verebileceğini göstermiş̧ir.

\section{Kaynakça}

Alkan, B. B., Atakan, C., \& Alkan, N. (2018). Dayanıklı lineer diskriminant analizi için yeni bir yaklaşım. Erciyes Üniversitesi Fen Bilimleri Enstitüsü Fen Bilimleri Dergisi, 34(2), 12-19.

Amann, R. P., \& Waberski, D. (2014). Computer-assisted sperm analysis (CASA): capabilities and potential developments. Theriogenology, 81(1), 5-17.

Bidgoli, A. A., Komleh, H. E., \& Mousavirad, S. J. (2015, November). Seminal quality prediction using optimized artificial ne ural network with genetic algorithm. In 2015 9th International Conference on Electrical and Electronics Engineering (ELECO) (pp. 695-699). IEEE.

Candemir, C. (2018). Estimating the semen quality from life style using fuzzy radial basis functions. Int J Mach Learn Comput, 8(1), 44-8.

Chia, S. E., Ong, C. N., Chua, L. H., Ho, L. M., \& Tay, S. K. (2000). Comparison of zinc concentrations in blood and seminal plasma and the various sperm parameters between fertile and infertile men. Journal of andrology, 21(1), 53-57

Demirci, N. (2014). Male Fertility and Risky Lifestyle Behaviors. Florence Nightingale Hemşirelik Dergisi, 22(1), 39-45.

Gil, D., Girela, J. L., De Juan, J., Gomez-Torres, M. J., \& Johnsson, M. (2012). Predicting seminal quality with artificial intelligence methods. Expert Systems with Applications, 39(16), 12564-12573.

Gökçe, A., Gül, D., Direk, H. C., Çimen, H. İ., \& Halis, F. (2018). Cinsel perhiz süresi ve semen parametreleri arasındaki ilişki. Androloji Bülteni, 2018;20:11-15

Gültepe, Y. Makine Öğrenmesi Algoritmaları ile Hava Kirliliği Tahmini Üzerine Karşılaştırmalı Bir Değerlendirme. Avrupa Bilim ve Teknoloji Dergisi, (16), 8-15.

Gümüş̧̧ü, A., Karadağ, K., Çalişkan, M., Tenekecı, M. E., \& Akaslan, D. (2018, May). Gender classification via wearable gait analysis sensor. In 2018 26th Signal Processing and Communications Applications Conference (SIU) (pp. 1-4). IEEE.

Gürbüz, B., Yalti, S., Fiçicioğlu, C., \& Zehi r r, K. (2003). Relationship between semen quality and seminal plasma total carnitine in infertile men. Journal of Obstetrics and Gynaecology, 23(6), 653-656.

Hamameh S, Gatti J-L. Role of the ionic environment and internal pH on sperm activity. Hum Reprod Suppl 1998;4:20-30.

Hamlacı, Y., Yılmaz, B., \& Özerdoğan, N. Çalışma hayatının erkek üreme sağlığına etkisi. Androloji Bülteni, 19(1), 16-21.

Helwan, A., Khashman, A., Olaniyi, E. O., Oyedotun, O. K., \& Oyedotun, O. A. (2016). Seminal quality evaluation with RBF neural network. Bulletin of the Transilvania University of Brasov. Mathematics, Informatics, Physics. Series III, 9(2), 137.

Irgens, Å., Krüger, K., \& Ulstein, M. (1999). The effect of male occupational exposure in infertile couples in Norway. Journal of occupational and environmental medicine, 41(12), 1116-1120.

Latif, T., Kold Jensen, T., Mehlsen, J., Holmboe, S. A., Brinth, L., Pors, K., ... \& Lindahl-Jacobsen, R. (2017). Semen quality as a predictor of subsequent morbidity: a Danish Cohort Study of 4,712 men with long-term follow-up. American journal of epidemiology, 186(8), 910-917.

Pesch, S., Bergmann, M., \& Bostedt, H. (2006). Determination of some enzymes and macro-and microelements in stallion seminal plasma and their correlations to semen quality. Theriogenology, 66(2), 307-313.

Ramlau-Hansen, C. H., Thulstrup, A. M., Aggerholm, A. S., Jensen, M. S., Toft, G., \& Bonde, J. P. (2006). Is smoking a risk factor for decreased semen quality? A cross-sectional analysis. Human Reproduction, 22(1), 188-196.

Rowe, P. J., Comhaire, F. H., Hargreave, T. B., \& Mahmoud, A. M. (2000). WHO manual for the standardized investigation and diagnosis of the infertile male. Cambridge University Press.

Ruiz-Pesini, E., Lapeña, A. C., Díez, C., Álvarez, E., Enríquez, J. A., \& López-Pérez, M. J. (2000). Seminal quality correlates with mitochondrial functionality. Clinica Chimica Acta, 300(1-2), 97-105.

Sanocka-Maciejewska, D., Ciupińska, M., \& Kurpisz, M. (2005). Bacterial infection and semen quality. Journal of reproductive immunology, 67(1-2), 51-56. 
Sevli, O. Göğüs Kanseri Teşhisinde Farklı Makine Öğrenmesi Tekniklerinin Performans Karşılaştırması. Avrupa Bilim ve Teknoloji Dergisi, (16), 176-185.

Shiva, M., Gautam, A. K., Verma, Y., Shivgotra, V., Doshi, H., \& Kumar, S. (2011). Association between sperm quality, oxidative stress, and seminal antioxidant activity. Clinical biochemistry, 44(4), 319-324.

Simfukwe, M., Kunda, D., \& Chembe, C. (2015). Comparing Naive Bayes Method and Artificial Neural Network for Semen Quality Categorization. International Journal of Innovative Science, Engineering \& Technology, 2(7), 689-694.

Stutz, G., Zamudio, J., Santillán, M. E., Vincenti, L., De Cuneo, M. F., \& Ruiz, R. D. (2004). The effect of alcohol, tobacco, and aspirin consumption on seminal quality among healthy young men. Archives of Environmental Health: An International Journal, $59(11), 548-552$.

Tapısız, O. L., Altınbaş, S. K., Abike, F., \& Göktolga, U. (2012). Semen Analysis From A Point Of View Of Gynecologist And Recent Developments. Journal of Turkish Society of Obstetrics and Gynecology, 9(1), 25-31.

Uyar, A., Bener, A., \& Ciray, H. N. (2015). Predictive modeling of implantation outcome in an in vitro fertilization setting: an application of machine learning methods. Medical Decision Making, 35(6), 714-725.

Wang, H., Xu, Q., \& Zhou, L. (2014). Seminal quality prediction using clustering-based decision forests. Algorithms, 7(3), 405-417.

World Health Organization. WHO laboratory manual for the examination and processing of human semen, 5th ed. Geneva: WHO Press; 2010. Available from: http://apps.who.int/iris/ bitstream/10665/44261/1/9789241547789_eng.pdf

Xu, D. X., Shen, H. M., Zhu, Q. X., Chua, L., Wang, Q. N., Chia, S. E., \& Ong, C. N. (2003). The associations among semen quality, oxidative DNA damage in human spermatozoa and concentrations of cadmium, lead and selenium in seminal plasma. Mutation Research/Genetic Toxicology and Environmental Mutagenesis, 534(1-2), 155-163.

Yücelbaş, Ş., \& Yücelbaş, C. (2019). Temel Bileşen Analizi Yöntemleri Kullanarak Parkinson Hastalığının Otomatik Teşhisi. Avrupa Bilim ve Teknoloji Dergisi, (16), 294-300.

https://www.mathworks.com, erişim tarihi 01.08.2019 